\author{
Zdenka Koharić, odvjetnica
}

\title{
PRIMJENA PRAKSE EUROPSKOG SUDA U POREZNIM STVARIMA
}

\author{
UDK: 336. 2 (4) \\ Primljeno: 15. 12. 2017. \\ Stručni rad
}

\begin{abstract}
U radu autorica naglašava važnost jednakog tumačenja i primjene prava u svim državama članicama. Prema svim ispitivanjima, uz primjedbe visokog poreznog opterećenja i to posebno na rad, glavna zamjerka poreznom sustavu Republike Hrvatske jest pravna nesigurnost. Pravna nesigurnost u poreznom sustavu najveći je neprijatelj stabilnosti gospodarstva i njegovu razvoju. Ukazujući na praksu Europskog suda u poreznim stvarima autorica zaključuje da je slaba konkurentnost domaćeg gospodarstva glavna prepreka stranim investicijama.
\end{abstract}

Ključne riječi: Europski sud, odluke u poreznim stvarima

\section{UVOD}

Cilj ovog rada jest naglasiti važnost upravo jednakog tumačenja i primjene prava u svim državama članicama. Prema svim ispitivanjima, uz primjedbe visokog poreznog opterećenja i to posebno na rad, glavna zamjerka poreznom sustavu Republike Hrvatske jest pravna nesigurnost. Pravna nesigurnost u poreznom sustavu najveći je neprijatelj stabilnosti gospodarstva i njegovu razvoju. Slaba konkurentnost domaćeg gospodarstva glavna je prepreka stranim investicijama.

Pristupanjem Republike Hrvatske Europskoj uniji, Republici Hrvatskoj ostvarilo se pravo pristupa Europskom sudu. Sud Europske unije osigurava da se pravo Europske unije jednako tumači i primjenjuje u svim zemljama Unije, osigurava da zemlje i institucije Europske unije poštuju pravo Europske unije.

Presude Suda Europske unije prvenstveno predstavljaju izvor prava (presedani) kod tumačenja pitanja oporezivanja kako direktnim tako i indirektnim porezima. U odsustvu presuda Suda Europske unije, hrvatski sudovi mogu se obratiti direktno Sudu Europske unije za tumačenje u slučajevima poreznog postupka kod kojeg nema pravnih lijekova na raspolaganju. Nadalje, izvan sudskog procesa, porezni obveznici mogu koristiti institut postupaka zbog povrede (complaints, infringement procedure) ispred Europske komisije u slučajevima kada zakoni Republike Hrvatske nisu usklađeni s direktivama i osnovnim načelima propisanima Ugovor o funkcioniranju Europske unije.

Primarni izvor prava u okviru direktnih poreza jest Ugovor o funkcioniranju Europske unije koji ne propisuje konkretna pravila za oporezivanje porezom 
na dobit/porezom po odbitku već se tumačenja temelje na osnovnim načelima propisanima navedenim Ugovorom, kao što su:

$>$ Porezi ne smiju narušiti slobodu kretanja odnosno prekogranične usluge,

$>$ Porezi ne smiju narušiti tržišno natjecanje (npr kroz državne potpore ili slične mjere),

$>$ Ne smije doći do diskriminacije na temelju nacionalnosti (rezidentnosti).

U okviru oporezivanja indirektnim porezima (porez na dodanu vrijednost, trošarine itd.), Sud Europske unije ispituje je li sekundarno pravo (na primjer Direktiva Vijeća 2006/112/EZ o zajedničkom sustavu poreza na dodanu vrijednost) ispravno ugrađeno u nacionalno zakonodavstvo.

Prema izraženom stavu Ministarstva financija Republike Hrvatske, porezni obveznici mogu se pozivati na presude Suda Europske unije samo u poreznim pitanjima koja su nastala nakon ulaska Republike Hrvatske u Uniju. Međutim, navedeni stav je suprotan tumačenju Suda Europske unije koji je u svojoj presudi Bulves AD protiv Bugarske (3991/03) presuđivao o poreznim pitanjima nastalima prije ulaska Bugarske u Europsku uniju vodeći se činjenicom da je PDVzakonodavstvo na brojne načine pratilo odredbe Direktive Vijeća 77/388/EEC od 17. svibnja 1977. godine o usklađivanju zakonodavstva država članica koje se odnose na poreze na promet, poznate pod nazivom šesta PDV-direktiva koja je u to vrijeme bila temelj sustava PDV-a u Europskoj uniji.

Republika Hrvatska uvela je porez na dodanu vrijednost kao inačicu poreza na promet 1. siječnja 1998. godine i time propisala osnovna načela oporezivanja porezom na dodanu vrijednost temeljena većinom na spomenutoj direktivi. Štoviše, kroz izmjene Zakona o porezu na dodanu vrijednost koje su stupile na snagu 1. siječnja 2010. godine, Republika Hrvatska se dodatno približila direktivi kroz uvođenje funkcionalnih oslobođenja od oporezivanja porezom na dodanu vrijednost.

Hrvatska je tijekom pristupanja Uniji u skladu s ispunjavanjem pravnog kriterija za članstvo u Europskoj uniji imala obvezu preuzimanja i provedbe pravne stečevine Europske unije, cjelokupnog korpusa prava i obveza koji povezuje države članice. Potpisivanjem Sporazuma o stabilizaciji i pridruživanju 2001. godine, Republika Hrvatska je preuzela obvezu usklađivanja nacionalnog zakonodavstva s pravnom stečevinom EU-a, što znači i obvezu interpretacije prava s praksom EU-a.

Obveza primjene europskog prava proizlazi i iz Ustava Republike Hrvatske kojim se jamči ostvarivanje prava koja proizlaze iz pravne stečevine Europske unije, izjednačenih s ostvarivanjem prava koja su zajamčena hrvatskim pravnim poretkom. Hrvatski sudovi štite subjektivna prava utemeljena na pravnoj stečevini Europske unije.

Važno je napomenuti da se pravo Europske unije mora primjenjivati na način da se ocjenjuju svrha i cilj norme (teleološka metoda) i u odnosu na ostale odredbe ugovora (kontekstualna metoda) što zahtijeva napuštanje isključivo gramatičke metode. 


\section{POREZNO RELEVANTNI POSTUPCI PRED SUDOM EUROPSKE UNIJE}

Postoje dva relevantna postupka koja poreznim obveznicima pružaju dodatnu zaštitu prilikom primjene poreznih zakonodavstava:

$>$ Prethodne odluke - tumačenje prava

Ako nacionalni sud ima nedoumice povezane $s$ tumačenjem ili valjanošću prava Europske unije, može se obratiti Sudu za pojašnjenje. Na isti način može utvrditi je li nacionalni zakon ili praksa usklađen s pravom Unije.

Postupci zbog povrede - provedba prava

Postupci zbog povrede pokreću se protiv nacionalnih vlada ako ne djeluju u skladu s pravom Europske unije. Mogu ih pokrenuti Europska komisija ili druga zemlja Europske unije. Utvrdi li se da je određena država članica pogriješila, ona mora odmah poduzeti mjere da ispravi pogrešku.

\section{1. Prethodne odluke}

Prethodne odluke predstavljaju obvezujuce smjernice za tumačenje primarnog i sekundarnog prava Europske unije.

Sud Unije daje prethodne odluke vezano uz tumačenje Ugovora i valjanosti tumačenja zakona Europske unije.

Kada je određeno pitanje upućeno pred sudom države članice, taj sud može, odnosno ima diskrecijsko pravo podnijeti zahtjev Sudu Europske unije za prethodnu odluku, ako smatra da je takvo tumačenje neophodno za donošenje presude. Međutim, i u slučaju odbijanja prijedloga stranke u sporu za upućivanje prethodnog pitanja Sudu Europske unije, sud je dužan obrazložiti razloge odbijanja. Isto nalaže ustavno načelo prava na pravično suđenje.

Kada je određeno pitanje upućeno sudu protiv čije odluke nema pravnog lijeka temeljem nacionalnog zakonodavstva, taj sud ima obvezu postaviti pitanje Sudu Europske unije.

Jedno od glavnih ograničenja koje se pojavljuje kod zahtjeva za upućivanje prethodnog pitanja jest „Acte claire doctrine”, izraženo u presudi Da Costa en Schaake NV and Others/Nederlandse Belastingadministratie, Joined Cases 28, 29, 30/62 (27 March 1963), na koju su se hrvatski sudovi dosad posebice pozivali. Navedena doktrina podrazumijeva situacije kada je primjena europskog prava toliko očita da ne ostavlja prostora za sumnju (reasonable doubt).

Međutim, cilj te doktrine nije olakšati obvezu sudova zadnje instance iz članka 267/3 Ugovora o funkcioniranju Europske unije već uspostaviti erga omnes učinak svojih odluka. Cijeneći složenost europskog prava, pozivanje na navedenu doktrinu zahtijeva izuzetno dobro poznavanje cjelokupne prakse Suda Europske unije.

Dalje, Sud Europske unije ne daje tumačenja teoretskih pitanja, odnosno kada zahtjev ne polazi od stvarnih činjenica glavnog postupka ili se radi o hipotetskom 
problemu ili kada Sud nema dostatnih činjeničnih i pravnih osnova za koristan odgovor.

Presude Suda Europske unije uvijek se odnose na konkretne porezne slučajeve. Međutim, njihov utjecaj ogleda se upravo u snazi interpretacije postojećih normi. Interpretacije su retroaktivne odnosno objašnjavaju značenje norme od trenutka kad je ona nastala, jer su sastavni dio norme koju objašnjavaju od trenutka od kada ona postoji.

Važno je naglasiti da izreka presude stvara pravo između stranaka u sporu. Međutim, obrazloženje odluka Suda Europske unije u kojemu se zauzima određeno pravno shvaćanje, značaj i doseg određene pravne norme ima obvezujući učinak na sve sudove država članica kod istog poreznog slučaja (erga omnes). Svoje kasnije odluke Sud Europske unije temeljit će na takvim pravnim shvaćanjima i često se poziva na raniju sudsku praksu. Države članice imaju obvezu poštovati i provoditi odluke Suda Europske unije. Nacionalni sud koji bi grubo zanemario raniju praksu Suda Europske unije može predstavljati osnovu za naknadu štete od strane države članice.

Europsko pravo nadređeno je nacionalnom pravu na svim razinama, uključujući zakone i Ustavno pravo. Nadređenost je načelo europskog prava.

\section{II.2 Postupci zbog povrede (complaints)}

Porezni obveznici mogu pokrenuti postupak zbog povrede u slučajevima kada domaći propisi krše europsku legislativu. Ovaj postupak ne podrazumijeva postojanje otvorenog poreznog postupka s poreznim vlastima. Navedeni postupak se, temeljem zahtjeva poreznog obveznika odnosno bilo koje zainteresirane strane, vodi između države članice i Europske komisije. Međutim, diskrecijsko je pravo Europske komisije uputiti zahtjev državi članici za rješavanje određene neusklađenosti.

\section{OSNOVA PRAKSE SUDA EUROPSKE UNIJE}

\section{III.1. Direktni porezi}

Prema europskom pravu, direktni porezi ostaju pod nacionalnom jurisdikcijom svake države članice, ali se europsko pravo mora poštovati:

$>$ Porezi ne smiju narušiti slobodu kretanja odnosno prekogranične usluge;

$>$ Porezi ne smiju narušiti tržišno natjecanje (npr. kroz državne potpore ili slične mjere);

$>$ Ne smije doći do diskriminacije na temelju nacionalnosti (rezidentnosti);

$>$ Primjena nekoliko principa (opća pravila iz primarnog prava te nekoliko sekundarnog prava);

$>$ Sud Europske unije pravde ispituje je li sekundarno pravo (Direktiva Vijeća 2011/96/EU o zajedničkom sustavu oporezivanja koji se primjenjuje na matična društva i društva kćeri iz različitih država 
članica) ispravno ugrađeno u nacionalno zakonodavstvo te Sud jedini ima pravo tumačenja europskog prava.

Sud Europske unije također ispituje krši li nacionalno zakonodavstvo primarno europsko pravo, a posebno krši li sljedeće principe:

$>$ slobodu kretanja dobara;

$>$ slobodu osnivanja (Art. 49 TFEU) i slobodu kretanja zaposlenika;

$>$ slobodu pružanja usluga (Art. 56 TFEU);

> slobodu kretanja kapitala (Art. 63 TFEU) i plaćanja.

\section{III.2. Indirektni porezi}

Sud Europske unije ispituje je li sekundarno pravo (na primjer Direktiva Vijeća 2006/112/EZ o zajedničkom sustavu poreza na dodanu vrijednost) ispravno ugrađeno u nacionalno zakonodavstvo.

\section{KADA DOLAZI DO KRŠENJA OSNOVNIH SLOBODA?}

Prema presudama Suda Europske unije, do kršenja osnovnih sloboda dolazi u sljedećim situacijama:

$>$ kada se iste situacije tretiraju drugačije ili

$>$ kada se različite situacije tretiraju jednako.

Stoga Sud Europske unije pravde prvo ispituje:

$>$ je li porezni obveznik koji posluje u inozemstvu u istoj situaciji kao domaći porezni obveznik;

$>$ je li strani porezni obveznik koji posluje na domaćem teritoriju u istoj situaciji kao domaći porezni obveznik (presuda Suda pravde EU - "Denkavit" C-170/05);

$>$ drugačiji tretman je opravdan jedino ako zadovoljava određeni legitimni cilj države članice i to prevladavajućom potrebom zaštite javnog interesa (princip proporcionalnosti);

$>$ strani i domaći porezni obveznici mogu jednako primjenjivati osnovne slobode.

\section{ODABRANE PRESUDE SUDA EUROPSKE UNIJE}

\section{Denkavit International BV, VITIC Amsterdam BV and Voormeer BV v Bundesamt für Finanzen (C-170/05)}

Navedena presuda govori o nejednakom tretmanu dividendi isplaćenih domaćim dioničarima u odnosu na inozemne dioničare. Naime, država članica nije oporezivala porezom po odbitku dividende isplaćene domaćim vlasnicima dok se porez po odbitku propisivao na dividende isplaćene inozemnim vlasnicima.

Takvim se propisom direktno narušavalo osnovno načelo slobode poslovanja „freedom of establishment” propisano Ugovorom o funkcioniranju Europske unije. 
Ta je presuda imala za posljedicu iniciranje zahtjeva za povrat poreza po odbitku od strane inozemnih vlasnika ${ }^{1}$.

\section{Finanzamt Gummersbach v Gerhard Bockemuhl (C-90/02)}

U navedenoj presudi radilo se o slučaju da fakturirana usluga nije provedena od strane društva čije se ime pojavilo na računima, nego od neke druge, nepoznate strane. Dakle, pravo na odbitak PDV-a bio je sporan jer primatelj usluge nije imao odgovarajuću, ispravnu fakturu.

Sud je presudio da kod mehanizma prijenosa porezne obveze, porezni obveznik koji je odgovoran za obračun PDV-a kao primatelj usluge, nije obvezan biti u posjedu računa kako bi mogao ostvariti svoje pravo na odbitak, odnosno posjedovanje računa nije preduvjet za odbitak PDV-a².

\section{Ecotrade (C-95/07 i C-96/07)}

U toj presudi radi se o tome da je porezna uprava utvrdila kako porezni obveznik nije prijavio izlazni PDV u razdoblju od četiri godine, dok mu se uskratilo povrat pretporeza za prve dvije godine, s obrazloženjem da je vrijeme za zahtjev za povrat pretporeza isteklo za poreznog obveznika (u skladu sa zakonom, porezne vlasti imaju pet godina za procjenu izlaznog poreza, a porezni obveznici imaju samo dvije godine od trenutka obračuna PDV-a zahtijevati odbitak pretporeza).

Sud je presudio da različiti rokovi za poreznu upravu i porezne obveznike ne krše načelo jednakosti, čak i ako je rok za poreznu upravu da utvrdi povrat pretporeza dulji nego pravo poreznog obveznika da traži povrat pretporeza.

Međutim, ograničavanje povrata pretporeza prema mehanizmu prijenosa porezne obveze - u slučaju poreznih obveznika s pravom na puni odbitak - nije dopušteno jer je mehanizam prijenosa porezne obveze čista formalna obveza i nesporazum ne može uskratiti pravo na odbitak ulaznog PDV-a ${ }^{3}$.

\section{Teleos PLC (C-409/04)}

U navedenom poreznom slučaju radilo se o fiktivnoj isporuci mobitela PDVregistriranom kupcu u inozemstvu zbog čega je isporuka tretirana isporukom

1 Usp. Denkavit International BV, VITIC Amsterdam BV and Voormeer BV v Bundesamt für Finanzen. (Joined cases C-283/94, C-291/94, C-292/94, -C-170/05); usp. HYPERLINK "https://www. google.hr/search?hl=hr\&tbo=p\&tbm=bks\&q=inauthor:\%22Salvador+Trinxet+Llorca\%22" Salvador Trinxet Llorca, European Union Direct Taxes, Asset Protection Publishing, 2010., p. 145

2 Usp. Case C-90/02, Finanzamt Gummersbach v Gerhard Bockemühl (Reference for a preliminary ruling from the Bundesfinanzhof),http://curia.europa.eu/juris/showPdf.jsf?text=\&docid=55421\&pageInd $\mathrm{ex}=0 \&$ doclang $=$ en $\&$ mode $=$ req $\&$ dir $=\&$ occ $=$ first $\&$ part $=1 \&$ cid $=1103130$

3 Judgment of the Court (Third Chamber) of 8 May 2008. Ecotrade SpA v Agenzia delle Entrate Ufficio di Genova 3. Reference for a preliminary ruling: Commissione tributaria provinciale di Genova - Italy. Sixth VAT Directive - Reverse charge procedure - Right to deduct - Time-bar - Irregularity in accounts and tax returns affecting transactions subject to the reverse charge procedure. Joined cases HYPERLINK "http://curia.europa.eu/juris/liste.jsf?num=C-95/07\&language=en" \t "_blank" C-95/07 and C-96/07. http://curia.europa.eu/juris/liste.jsf?language=en\&num=C-95/07 
oslobođenom od PDV-a (isporuka u drugu državu članicu). Kako bi opravdao oslobođenje od PDV-a, porezni obveznik se pozvao na komercijalni cestovni dokument kao dokaz da je roba bila isporučena u drugu državu članicu. Međutim, naknadno se pokazalo da je cestovni dokument neispravan, te stoga porezno tijelo nije prihvatilo PDV-oslobođenje.

Sud je presudio da država članica ne može osporiti dobavljaču zaračunati PDV na robu, ako se informacija (dokument) na koju se pozvao naknadno pokaže pogrešnom ako dobavljač posluje u dobroj vjeri i dostavi dokaze o pravu na oslobođenu isporuku unutar EU te ako nije umiješan u utaju poreza i poduzima sve razumne mjere u svojoj moći kako bi se osiguralo da transakcija nije dovela do njegovog sudjelovanja u utaji poreza ${ }^{4}$.

\section{FCE Bank (C-210/04)}

Navedeni porezni slučaj odnosi se na usluge upravljanja, savjetovanja, obradu podataka, obuku zaposlenika, opskrbu i upravljanje softverom, pružene iz sjedišta UK banke, FCE Bank, svojoj podružnici u Italiji, FCE IT, grana FCE banke. Zbog toga što podružnica nije imala pravo na odbitak PDV-a u potpunosti, društvo je pretrpjelo trošak PDV-a u Italiji na navedene transakcije. Društvo je na temelju argumentacije da - kako su matično društvo i podružnica jedna pravna osoba te transakcije između njih nisu relevantne za svrhe PDV-a - tražilo povrat poreza putem stalnog mjesta poslovanja, sjedišta u Italiji, koji je bio odbijen.

Sud je presudio da isporuke pružene od matičnog društva svojoj podružnici, ili isporuke pružene od podružnice prema sjedištu, ili isporuke pružene između podružnica iste pravne osobe - nisu predmet oporezivanja PDV-om.

Presudu potvrđuje i mišljenje hrvatske Porezne uprave koje navodi sljedeće: „U slučaju kada su inozemni poduzetnik i njegova tuzemna poslovna jedinica matica i podružnica, tada između njih ne postoji obavljena usluga, u smislu odredbe čl. 2(1) Zakona o porezu na dodanu vrijednost, koja podliježe oporezivanju porezom na dodanu vrijednost" ${ }^{\text {"5 }}$.

\section{Rompelman \& Rompelman (C- 268/83)}

U tom poreznom slučaju radilo se o tome da je porezni obveznik kupio dio zgrade u izgradnji s namjerom da se u budućnosti (kad se zgrada završi) prostor iznajmi komercijalnim najmoprimcima. Porezni obveznik je izabrao mogućnost tretiranja takve isporuke oporezivom PDV-om (isporuke koja je inače oslobođena

${ }^{4}$ Case C-409/04, The Queen, on the application of: Teleos plc and Others, $v$ Commissioners of Customs \& Excise, (Reference for a preliminary ruling from the High Court of Justice of England and Wales, Queens Bench Division, http://curia.europa.eu/juris/showPdf.jsf?docid=72135\&doclang=en

5 Judgment of the Court (Second Chamber) of 23 March 2006., Ministero dell'Economia e delle Finanze and Agenzia delle Entrate v FCE Bank plc.Reference for a preliminary ruling: Corte suprema di cassazione - Italy. Sixth VAT Directive - Articles 2 and 9 - Fixed establishment - Non-resident company Legal relationship - Cost-sharing agreement - OECD Convention on double taxation - Meaning of 'taxable person' - Supply of services effected for consideration - Administrative practice.Case C-210/04.http:// curia.europa.eu/juris/liste.jsf?language $=$ en $\&$ num $=C-210 / 04$ 
PDV-a) te bi u budućnosti zaračunavao PDV na najam. S obzirom na to da je porezni obveznik imao namjeru obavljanja oporezivih isporuka najma, odbio je ulazni PDV u vezi sa stjecanjem.

Porezna uprava je osporila odbitak ulaznog PDV-a na stjecanje zgrade, uz obrazloženje da se ne provodi ekonomska aktivnost te da nema statusa oporezive osobe u tom trenutku.

Sud je presudio da se pod pojmom „ekonomska aktivnost” podrazumijevaju i sve pripremne radnje u vezi s oporezivom isporukom te je dopustio odbitak ulaznog PDV-a ${ }^{6}$.

\section{INZO (C- 110/94)}

Porezni obveznik je bilo dioničko društvo čije je poslovanje razvoj desalinacijskih procesa. Porezni obveznik je proveo studiju o profitabilnosti specifičnog projekta te je odbio ulazni PDV povezan sa studijom. Međutim, projekt je identificirao brojne probleme s profitabilnošću, većina investitora se povukla te se odustalo od projekta. U međuvremenu, porezni obveznik je likvidiran.

Porezna uprava je osporila odbitak ulaznog PDV-a, uz obrazloženje da porezni obveznik nije obavljao nikakvu oporezivu aktivnost.

Sud je presudio da se provođenje studije o profitabilnosti vezane za planiranu aktivnost može smatrati ekonomskom aktivnošću za potrebe PDV-a, čak i ako je svrha studije istražiti do kojeg je stupnja planirana aktivnost profitabilna.

Navodi se: „... koja god je svrha ili rezultat takve aktivnosti” (članak 9. PDV Direktive), neopravdana porezna diskriminacija bi mogla nastati između poduzetnika koji već obavljaju oporezive transakcije i onih koji snose izdatke (ulaganja), u nastojanju da će započeti posao koji će kasnije proizvesti oporezivi promet / transakcije"7.

\section{RR Donnelley Global Turnkey Solutions Poland sp. z o.o. (C- 155/12)}

Porezni obveznik je obavljao složene logističke usluge u Poljskoj za dobrobit ugovornih partnera bez sjedišta ili stalne poslovne jedinice u Poljskoj. Usluge koje su bile ugovorene su: prijem robe na skladište, svrstavanje na odgovarajuće police, skladištenje robe, pakiranje robe za kupce i izdavanje, istovar i utovar robe. Namjera stranaka nije bila odobravanje primatelju usluge prava na korištenje prostora za skladištenje, već da usluga uključuje čuvanje robe u nepromijenjenom stanju i pružanje svih popratnih usluga.

\footnotetext{
6 Judgment of the Court (Second Chamber) of 14 February 1985. D.A. Rompelman and E.A. Rompelman-Van Deelen v Minister van Financiën. Reference for a preliminary ruling: Hoge Raad Netherlands. Harmonisation VAT - Sixth directive - Concept of taxable person. Case 268/83., http://curia. europa.eu/juris/liste.jsf? Language $=$ en \&num $=$ C-268/83

7 Judgment of the Court (Fifth Chamber) of 29 February 1996., Intercommunale voor zeewaterontzilting (INZO) v Belgian State. Reference for a preliminary ruling: Rechtbank van eerste aanleg Brugge - Belgium. VAT - Concept of economic activity - Status of taxable person - Activity confined to a profitability study for a project, followed by the abandonment of the project. Case C-110/94. $\mathrm{http} / /$ curia.europa.eu/juris/liste.jsf?language $=$ en \&num $=\mathrm{C}-110 / 94$
} 
Sudu se postavilo pitanje treba li navedene usluge pružene od strane društva oporezivati prema mjestu primatelja ( $\mathrm{tj}$. izvan Poljske) ili usluge treba tretirati kao povezanima s nekretninama, odnosno oporezivati ih na istom mjestu gdje se nekretnina nalazi (na teritoriju Poljske).

Sud je presudio da bi se složena usluga skladištenja dobara trebala smatrati uslugom u vezi s nekretninom samo ako su ispunjeni sljedeći uvjeti:

$>$ skladištenje dobara predstavlja glavnu uslugu, $\mathrm{i}$

$>$ korisniku usluge je omogućeno korištenje nekretnine u cijelosti ili njezinog točno određenog dijela ${ }^{8}$.

\section{Fast Bunkering Klaipėda (C-526/13)}

Isporuka goriva direktno na brodove koji plove na otvorenom moru oslobođena je PDV-a bez obzira na to što je prvotna isporuka, isporuka posredniku koji dalje isporučuje brodovima. Postavilo se pitanje može li prva isporuka biti oslobođena PDV-a.

Sud je presudio kako nacionalni sud treba procijeniti je li isporuka posredniku izvršena u istom trenutku kad je dobro došlo na raspolaganje brodu, u kom slučaju bi se isporuku posredniku moglo tretirati oslobođenom isporukom kao da se isporuka napravila brodu?

\section{SVEDA (C-126/14)}

Sudu je postavljeno pitanje može li se odbiti pretporez za gradnju staze koja će se koristiti besplatno, ali će privući posjetitelje na lokaciju gdje poduzetnik planira obavljati isporuke dobara i usluga, iako ne postoji direktna povezanost.

Sud je presudio da postoji pravo na odbitak pretporeza iako nema direktne povezanosti s oporezivom isporukom ${ }^{10}$.

8 Judgment of the Court (First Chamber), 27 June 2013. Minister Finansów v RR Donnelley Global Turnkey Solutions Poland sp. z o.o. Request for a preliminary ruling from the Naczelny Sąd Administracyjny VAT - Directive 2006/112/EC - Articles 44 and 47 - Place where taxable transactions are deemed to be carried out - Place of supply for tax purposes - Concept of 'supply of services connected with immovable property' - Complex cross-border service relating to the storage of goods. Case C-155/12., http://curia.europa.eu/juris/liste.jsf?num=C-155/12\&language =EN

9 Judgment of the Court (Fourth Chamber) of 3 September 2015. UAB "Fast Bunkering Klaipèda"" v Valstybinè mokesčiu inspekcija prie Lietuvos Respublikos finansų ministerijos. Request for a preliminary ruling from the Mokestinių ginčų komisija prie Lietuvos Respublikos vyriausybės. Reference for a preliminary ruling - Taxation — Value Added Tax (VAT) — Directive 2006/112/EC — Article 148(a) - Supply of goods - Definition - Exemption - Supply of goods for the fuelling and provisioning of vessels used for navigation on the high seas - Supplies to intermediaries acting in their own name. Case C-526/13, http://curia.europa.eu/juris/liste.jsf?language $=$ en\&num=C-526/13

10 Judgment of the Court (Fifth Chamber) of 22 October 2015. UAB "Sveda" v Valstybinė mokesčių inspekcija prie Lietuvos Respublikos finansų ministerijos. Request for a preliminary ruling from the Lietuvos vyriausiasis administracinis teismas. Reference for a preliminary ruling — VAT — Directive 2006/112/EC - Article 168 - Right of deduction - Deduction of input VAT on the acquisition or production of capital goods - Recreational path directly intended for use by the public free of charge Use of the recreational path as a means of carrying out taxed transactions. Case C-126/14; http://curia. europa.eu/juris/liste.jsf?num $=\mathrm{C}-126 / 14$ 


\section{PPUH Stehcemp (C-277/14)}

Postavilo se pitanje smije li nacionalni propis poreznom obvezniku onemogućiti pravo na odbitak pretporeza koji se mora platiti ili koji je plaćen za robu na temelju toga što je račun izdao trgovac kojega, s obzirom na kriterije određene tim propisom, treba smatrati nepostojećim i na temelju toga što nije moguće utvrditi identitet stvarnog dobavljača robe.

Sud je presudio da postoji pravo na odbitak pretporeza iako je isporuka primljena od nepostojećeg trgovca, jer je pravo na odbitak pretporeza temeljno načelo zajedničkog sustava PDV-a koje se u načelu ne može ograničiti i može se odmah primjenjivati na sve poreze koji se primjenjuju na ulazne transakcije ${ }^{11}$.

\section{UMJESTO ZAKLJUČKA}

Europski parlament je u više navrata naglašavao da bi europsko pravo ostalo mrtvo slovo na papiru ukoliko se ne bi ispravno primjenjivalo u državama članicama, uključujući i nacionalne sudove, koji su stoga ključ europskog pravosudnog sustava i igraju glavnu ulogu u uspostavi europskog pravnog poretka ${ }^{12}$.

\section{APPLICATION OF EUROPEAN COURT PRACTICE IN TAXATION MATTERS}

Here the author emphasises the importance of equal interpretation and the application of law for all member states. According to all investigations, together with the comment on the high taxation burdems, especially on work, the main criticism of the taxation system in the Republic of Croatia is legal insecurity. Legal uncertainty in the taxation system is the worst enemy to economic instability and its development. Pointing out Europen Court practice in taxation matters, the author concludes that poor competiveness of domestic ecomony is the main hurdle for foreign investors.

Key words: European Court, judgemets in taxation matters

${ }^{11}$ Judgment of the Court (Fifth Chamber) of 22 October 2015. PPUH Stehcemp sp. j Florian Stefanek, Janina Stefanek, Jaroslaw Stefanek v Dyrektor Izby Skarbowej w Lodzi. Request for a preliminary ruling from the Naczelny Sąd Administracyjny. Reference for a preliminary ruling — Taxation — Value added tax - Sixth Directive - Right of deduction - Refusal - Sale by an entity regarded as non-existent. Case C-277/14 ; http://curia.europa.eu/ juris/liste.jsf?language=en\&num=C-277/14

12 Usp. EU Legislation in Progress, https://epthinktank.eu/eu-legislation-in-progress/; John Coughlan, Judicial training in the EU: a study for the European Parliament, https://link.springer.com/ article/10.1007/s12027-012-0257-9 